\title{
EVALUATION OF BALLOON ANGIOPLASTY IN INFRAPOPLITEAL INTERVENTIONS FOR PATIENTS WITH CRITICAL LIMB ISCHEMIA
}

\author{
By
Moaaz Abd Allah Ramadan, Mohamed Kamel Al-Mezayen and Abd Al- Azez Ahmed Abd El-Hafez \\ Department of General Surgery, Faculty of Medicine, Al-Azhar University, Cairo, Egypt \\ Corresponding author: Moaaz Abd Allah Ramadan
}

Mobile: 01004595152, E-mail: drmizo9010@gmail.com

\begin{abstract}
Background: Peripheral arterial occlusive disease (PAOD) is a major disease that limits active aging in elderly people. Complications of PAOD are the leading cause of hospitalization and amputation for people with lower limb ischemia, and account for billion-dollar expenditures annually around the world.

Objective: To assess the balloon dilation angioplasty in limb salvage rate and patency in infra-popliteal arterial occlusive disease.

Patients and methods: This study was carried out as a prospective study, in Al-Azhar University Hospitals and 6 October HIO hospital on 20 diabetic patients with critical limb ischemia as defined by Rutherford classification, between Jan, 2019 and July, 2019. Written consents were obtained from all patients. Every patient received an explanation to the purpose of the study.

Results: The present study was conducted on 20 diabetic patients, 11 males (55\%) and 9 females $(45 \%)$.Their ages ranged between 50 years and 87 years with a mean age of 66.7. Limb salvage was defined as freedom from major amputation, toe, ray, or trans-metatarsal amputations were considered as minor amputations.

The limb salvage after 6 months was 70\%, clinical successes were defined as relief of rest pain or improve healing of the ulcer and limb salvage, based on Rutherford categories. Of 3 patients $(15 \%)$ suffering from rest pain, Percutaneous Transluminal Angioplasty (PTA) succeeded in 2 patients (66.7\%) and became nondisabling cludicants at more than 400m. PTA failed in one patient (33.3\%), who underwent redo angioplasty, but failed again. He received conservative treatment in the form of anticoagulants, antiplatelets and vasodilators without improvement and ended by major amputation. Of 17 patients (85\%) suffering from minor tissue loss, PTA succeeded in 11 patients $(64.7 \%)$ improve healing was achieved, PTA failed in 6 patients $(35.3 \%)$ four patients underwent femoro-distal bypass surgery, but failed and diabetic foot infection with osteomyelitis reached up to ankle joint and ended by major amputation. Two patients underwent above knee amputation before six months. Two patients underwent below knee amputation at six months. The other 2 patients underwent above knee amputation before six months due their deterioration of their general condition.
\end{abstract}

Conclusion: Tibial angioplasty demonstrated its feasibility, safety and effectiveness in the treatment of diabetic patients with CLI.

Keywords: Tibialangioplasty, infrapopliteal arterial disease. 


\section{INTRODUCTION}

Peripheral arterial occlusive disease (PAOD) is a major disease that limits active aging in elderly people. Complications of PAOD are the leading cause of hospitalization and amputation for people with lower limb ischemia, and account for billion-dollar expenditures annually in the United States (Frykberg et al., 2017).

CLI estimated to develop in 500 to 1000 individuals per million persons per year in the general populations. CLI has important functional implications and a major impact on the quality of life with high morbidity and mortality rates. The quality of life indices of patients with CLI have been reported to be similar to those of terminal cancer patients (Frykberg et al., 2017).

Critical limb ischemia (CLI) resulting from occluded or stenotic crural vessels remains a challenge for vascular surgeons. Most of these patients have extended diffuse three-vessel disease only $20-30 \%$ present with a simple focal lesion and good runs off. Patients are usually elderly people, with severe co-morbidity, at high risk for surgery, and with a limited life expectancy. Twenty-five percent will die during the first year of follow up from vascular or nonvascular event (Capek et al., 2019).

Endovascular treatment of infrapopliteal vessels is a low risk, minimally invasive procedure which rarely compromises later distal bypass surgery and can be performed under local anesthesia. It shortens the operation and hospitalization time and has an acceptable complication rate (Soder et al., 2010).
Development of lower profile angioplasty catheters for long segmental lesions, guide wires and advanced techniques such as subintimal angioplasty, and pedal puncture, angioplasty is now considered a feasible alternative for treatment of chronic atherosclerotic occlusive disease in crural and pedal vessels. In a recent meta-analysis of infrapopliteal angioplasty, technical and clinical success rates for short lesions of approximately $90 \%$ (Dorros et al., 2018).

\section{PATIENTS AND METHODS}

This study includes 20 patients (11 males and 9 females, and their age ranged between 50 and 78years).

Patients with critical limb ischemia as defined by Rutherford classification having lesions of infra-popliteal arterial segment, scheduled for limb revascularization using balloon dilation angioplasty, managed at Al-Azhar University Hospitals (Al Hussein and Bab Al-Sha'aria University Hospitals) and 6th October HIO Hospital between Jan 2019 and July 2019.

The diagnosis was based on clinical picture and imaging findings.

\section{Inclusion criteria:}

Patients with infrainguinal arterial occlusive disease who were diagnosed with the clinical presentations of incapacitating claudication or critical limb ischemia with angiographic confirmation of isolated infra-popliteal lesions.

\section{Exclusion criteria:}

- Patients with poor tibial collateral circulation, no distal or target runoff. 
- Mild claudicants or asymptomatic lesions (Rutherford 1, 2, 3).

- Severe (diabetic) foot infection or too extended gangrene that render the limb unsalvageable.

- Acute ischemia.

- Pregnancy.

- Known allergy to heparin, aspirin, or other antithrombotic agents.

- Short life expectancy <24 months 2ry to co-morbid Conditions.

All patients enrolled in the study were subjected to full history, general and local examination, and investigations including color duplex and CT angiography. Patients were grouped according to the modified Trans-Atlantic Inter-Society Consensus II (TASC II) in the management of PAD into 4 groups:

- Group A: Single stenosis shorter than $1 \mathrm{~cm}$.

- Group B: Multiple focal $(<1 \mathrm{~cm})$ stenosis of the tibial or peroneal arteries (including up to two focal stenosis at the tibial trifurcation) and short tibial or peroneal stenosis in conjunction with femoro-popliteal disease.

- Group C: Longer stenosis 1-4 cm and occlusions $1-2 \mathrm{~cm}$ as well as extensive stenosis at the tibial trifurcation.

- Group D: Occlusions longer than $2 \mathrm{~cm}$ and diffusely diseased tibial arteries.

Patients with TASC A, B and C were included in this study.

\section{Statistical analysis:}

Recorded data were analyzed using the statistical package for the social sciences, (SPSS, copy rights 2015). Descriptive analyses were done using life tables and Kaplan Meier curves were used to record amputation free survival and overall survival. A Spreadsheet was set up for data collection using Microsoft Excel ( ${ }^{\circ} 2015$ Microsoft). Statistical analysis will be done using SPSS ( ${ }^{\circ}$ Copyright IBM Corporation 1994, 2015). Results with $\mathrm{P}$ value $<0.05$ were considered significant.

\section{RESULTS}

The present study was conducted on 20 diabetic patients, 11 males $(55 \%)$ and 9 females $(45 \%)$. Their age ranged between
50 years and 87 years with a mean age of $66.7 \square 12.35$ (Table 1).

Table (1): Distribution of the studied patients regarding their age and sex

\begin{tabular}{|c|c|c|c|c|}
\hline \multirow{2}{*}{ Sex } & \multirow{2}{*}{$\mathbf{N}$} & \multirow{2}{*}{$(\%)$} & \multicolumn{2}{|c|}{ Age } \\
\cline { 4 - 5 } & & $(55 \%)$ & Range & Mean \pm S.D. \\
\hline Males & 11 & $(45 \%)$ & $55-87$ & $68.2 \pm 12.33$ \\
\hline Females & 9 & $(100 \%)$ & $50-87$ & $67.5 \pm 11.95$ \\
\hline Total & 20 & & $66.7 \pm 12.35$ \\
\hline
\end{tabular}


In this study patient's symptoms and sings varied, and tibial disease ranged from segmental stenosis to total occlusion assisted by Duplex, (Table 2).

Table (2): Symptoms and signs of 20 patients included in this study and categories of tibial disease

\begin{tabular}{|c|c|c|c|c|c|}
\hline $\begin{array}{c}\text { Symptoms and } \\
\text { signs }\end{array}$ & No. & $\boldsymbol{\%}$ & Category & No. & $\%$ \\
\hline Rest pain & 3 & $15 \%$ & A (stenosis 50-70\%) & $3 / 20$ & $15 \%$ \\
\hline Ischemic Ulcers & 5 & $25 \%$ & B (stenosis 70-90\%) & $5 / 20$ & $25 \%$ \\
\hline Gangrene: & 12 & $60 \%$ & & & \\
Toe & 5 & $25 \%$ & C (stenosis $>90 \%)$ & $12 / 20$ & $60 \%$ \\
Heel & 4 & $20 \%$ & & & \\
Forefoot & 3 & $15 \%$ & & & \\
\hline
\end{tabular}

Computerized Tomographic Angiography (CTA) showed that most of the lesions were in the peroneal and anterior tibial arterial territories $(60 \%$ and $40 \%$, respectively), a single tibial vessel was present in $50 \%$ of limbs (10/20) and two vessels in $45 \%(8 / 20)$. Only $5 \%$ of limbs had all three tibial vessels $(1 / 20)$, the patient's lesions were classified according to TASC classification, (Table 3).

Table (3): Localization, number of arteries, nature of lesions in the infrapopliteal arteries, and TASC classification

\begin{tabular}{|c|c|c|c|c|}
\hline Artery $\quad$ Parameters & No. & $(\%)$ & $\begin{array}{l}\text { Stenosis } \\
\text { (n) }\end{array}$ & $\begin{array}{l}\text { Occlusions } \\
\text { (n) }\end{array}$ \\
\hline TP Trunk & 5 & $25 \%$ & 4 & 1 \\
\hline ATA & 8 & $40 \%$ & 5 & 3 \\
\hline PTA & 6 & $30 \%$ & 4 & 2 \\
\hline $\mathrm{PA}$ & 12 & $60 \%$ & 9 & 3 \\
\hline Diseased vessels & \multicolumn{2}{|c|}{ No. } & \multicolumn{2}{|c|}{$\%$} \\
\hline 0 leg vessel & \multicolumn{2}{|c|}{0} & \multicolumn{2}{|c|}{$0 \%$} \\
\hline 1 leg vessel & \multicolumn{2}{|c|}{10} & \multicolumn{2}{|c|}{$50 \%$} \\
\hline 2 leg vessel & \multicolumn{2}{|c|}{9} & \multicolumn{2}{|c|}{$45 \%$} \\
\hline 3 leg vessel & \multicolumn{2}{|c|}{1} & \multicolumn{2}{|c|}{$5 \%$} \\
\hline 0 foot vessel & \multicolumn{2}{|c|}{2} & \multicolumn{2}{|c|}{$10 \%$} \\
\hline 1 foot vessel & \multicolumn{2}{|c|}{11} & \multicolumn{2}{|c|}{$55 \%$} \\
\hline 2 foot vessel & \multicolumn{2}{|c|}{7} & \multicolumn{2}{|c|}{$35 \%$} \\
\hline \multicolumn{5}{|l|}{ Site of Lesions } \\
\hline Isolated Tibial lesions & \multicolumn{2}{|c|}{20} & \multicolumn{2}{|c|}{$100 \%$} \\
\hline \multicolumn{5}{|l|}{ TASC classification } \\
\hline Group A & \multicolumn{2}{|c|}{7} & \multicolumn{2}{|c|}{$35 \%$} \\
\hline Group B & \multicolumn{2}{|c|}{8} & \multicolumn{2}{|c|}{$40 \%$} \\
\hline Group C & \multicolumn{2}{|c|}{2} & \multicolumn{2}{|c|}{$10 \%$} \\
\hline Group D & \multicolumn{2}{|c|}{3} & \multicolumn{2}{|c|}{15} \\
\hline
\end{tabular}

PTA resulted in less than $50 \%$ residual stenosis of the original lesion after balloon dilation. It was classified into three grades in accordance to angiographic findings, Optimal ( $<30 \%$ of residual stenosis) was achieved in 9 patients $(45 \%)$. Out of these 
9 patients, 4 were category A, 2 were category $\mathrm{B}$ and 3 were category C, Suboptimal (between 30-50 \% of residual stenosis) was achieved in 4 patients (20 $\%)$. Out of these, 4patients 1 was category A, 2 were category B and 1 was category
C, Failure ( $>50 \%$ of residual stenosis) to any significant dilation or failure to pass through the lesion (e.g.: a highly calcified total occlusion) this occurred in 7 patients (35\%). All of these patients have $>90 \%$ stenosis pre-procedure (Table 4).

Table (4): Results of PTA in studied patients (Angiographic patency)

\begin{tabular}{|c|c|c|c|c|c|}
\hline $\begin{array}{lr} & \text { Angiographic Patency } \\
\text { PTA } & \text { Rate (APR) }\end{array}$ & $\mathbf{N}$ & $(\%)$ & A & B & C \\
\hline Optimal $(<30 \%)$ & 9 & $45 \%$ & 4 & 2 & 3 \\
\hline Suboptimal (30-50\%) & 4 & $20 \%$ & 1 & 2 & 1 \\
\hline Failure & 7 & $35 \%$ & 0 & 0 & 7 \\
\hline Total & 20 & $100 \%$ & 5 & 4 & 11 \\
\hline
\end{tabular}

Clinical successes were defined as relief of rest pain or improve healing of the ulcer and limb salvage, based on Rutherford categories.

Of 3 patients (15\%) suffering from rest pain PTA succeeded in 2 patients $(66.7 \%)$ and became nondisabling cludicants at more than $400 \mathrm{~m}$.

- PTA failed in one patient $(33.3 \%)$ : he underwent redo angioplasty but failed again. He received conservative treatment in the form of anticoagulants, antiplatelet and vasodilators without improvement and ended by major amputation.
Of 17 patients (85\%) suffering from minor tissue loss PTA succeeded in 11 patients $(64.7 \%)$ : Improve Healing was achieved. PTA failed in 6 patients (35.3\%): 4 patients underwent femorodistal bypass surgery but failed and diabetic foot infection with osteomyelitis reached up to ankle joint and ended by major amputation: Two patients underwent above knee amputation before six months Two patients underwent below knee amputation at six months.

-The other 2 patients: underwent above knee amputation before six months due their deterioration of their general condition (Figure 1).

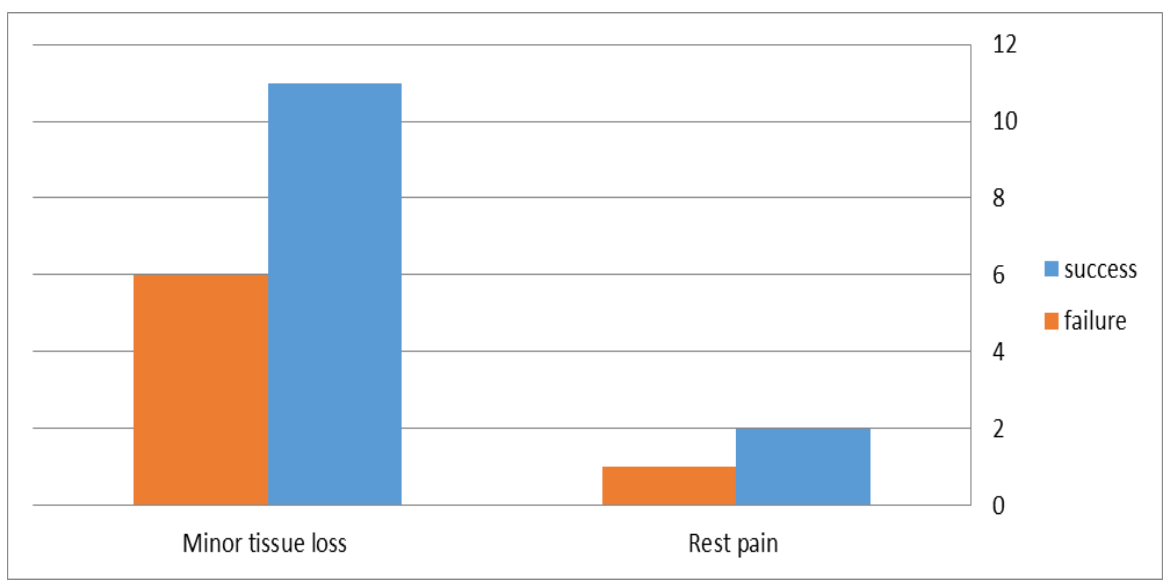

Figure (1): Analysis of the clinical factors in relation to PTA outcome 
One month after PTA, there was a statistically significant improvement $(\mathrm{P}<$ 0.001 ) between the pre-operative duplex evaluation of the stenosis and 1 month post PTA.

Three months after PTA, there was a statistically significant improvement $(\mathrm{P}<$
0.001) between the pre-operative duplex evaluation of the stenosis and 3 month post-operative evaluation.

The results of success by duplex study after one and three months were the same (Figure 2).

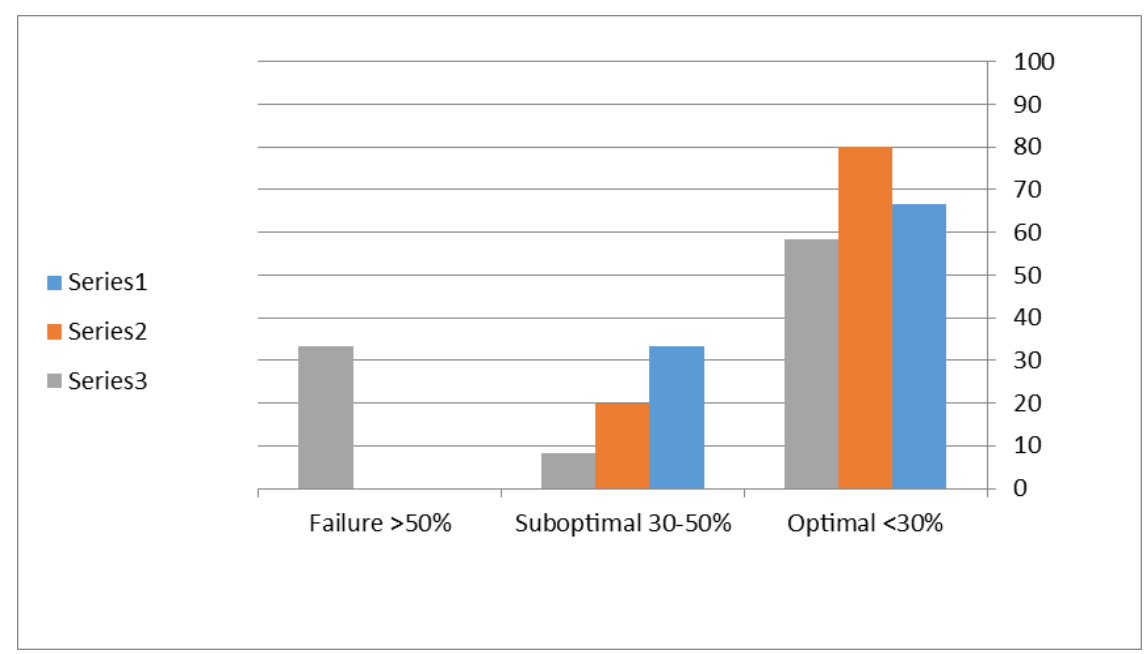

\section{Figure (2): Follow up results after one and three months}

Six months after PTA, Duplex evaluation six months after PTA, one out of five patients presented with pre-PTA stenosis $70-90 \%$ (category B) and the residual stenosis were $<30 \%$ (optimal), residual stenosis increased to $30-50 \%$ (suboptimal). Two patients (out of 12 patients) presented with pre-PTA stenosis more than $90 \%$ (category $C$ ) and the residual stenosis were $<30 \%$ (optimal), $<30-50 \%$ (suboptimal), residual stenosis increased to $>50 \%$ (i.e.: restenosis) they underwent redo PTA but failed and ended by above knee amputation (Figure 3).

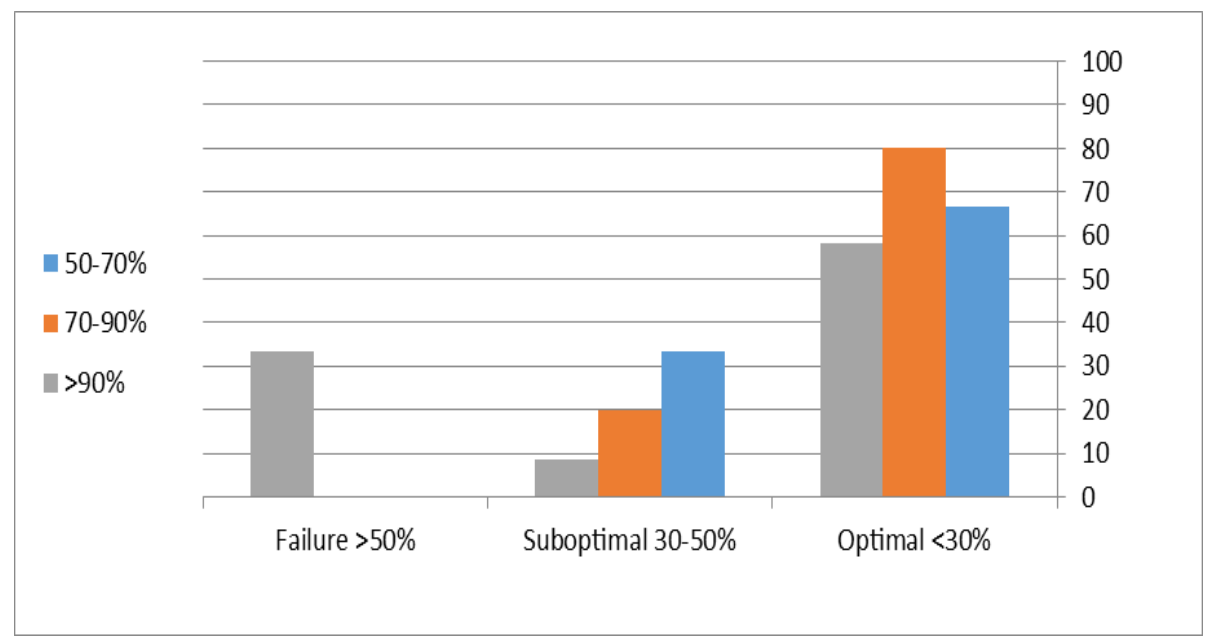

Figure (3): Follow up results after six months 
IV-Patency rates and limb salvage showed that $<50 \%$ diameter reduction (peak systolic velocity index < 2.4), 50\% or more diameter reduction (peak systolic velocity index > 2.4) and complete occlusion. Primary patency at 1 and 3 months was defined as Freedom from restenosis (Ultrasound patency); restenosis was defined by a peak systolic velocity index $>2.4$ at the target lesion, Limb salvage was defined as freedom from major amputation. Toe, ray, or transmetatarsal amputations were considered as minor amputations (Table 5).

Table (5): Primary patency rate and limb salvage after 1, 3 \&6 months

\begin{tabular}{|l|c|c|}
\hline \multicolumn{1}{|c|}{ Parameters } & N. & $(\mathbf{\% )}$ \\
\hline Primary Patency rate & & 70 \\
\hline After one month & 14 & 70 \\
\hline After 3 months & 14 & 60 \\
\hline After 6 Months & 12 & \\
\hline Limb salvage after PTA & & $65 \%$ \\
\hline Limb salvage after six month & 13 & \\
\hline
\end{tabular}

\section{DISCUSSION}

This study aimed to assess the results limb salvage rate, patency, improvement of clinical outcome according to Rutherford criteria of balloon angioplasty in infrapopliteal arterial occlusive disease. Of the 20 patients, $55 \%$ were males and $45 \%$ were females. The age of the patients ranged between 50 years and 87 years with a mean age $66.7 \pm 12.35$. Tan et al. (2010) reported that the age of the patients ranged between 20 and 54 years. Kristina et al. (2016) reported median age was 73 years (range, 39-94 years).

Clinical success was defined as relief of rest pain or healing of the ulcer and limb salvage, based on Rutherford categories. Of 3 patients (15\%) suffering from rest pain, 2 patients $(70 \%)$ become asymptomatic and 1 patient (30\%) underwent BK amputation. Of 12 patients $(60 \%)$ suffering for minor tissue loss, improve Healing was achieved in 8 patients $(75 \%)$ and 4 patients (25\%) underwent major amputations.
Tan et al. (2010), studded that the technical success was achieved in $90 \%$. A relatively low technical success rate (70\%). Todd et al. (2013) also reported a clinical success rate of $69 \%$ in a general population comprising of diabetic and non-diabetic patients. The mean time of ulcer healing after endovascular therapy is variable and frequently 12 months. Hynes et al. (2014) reported that clinical success is superior to angiographic patency and in the majority of cases repeated angioplasty can be performed if there is recurrence of ischemic symptoms or signs. Tibial PTA can also be performed after femoral angioplasty or bypass surgery, to improve outflow and hence patency of the proximally treated segment.

The primary patency rate was $80 \%$ at 1 month; $70 \%$ at 3 months and $60 \%$ at 6 months. The primary technical success rate was achieved in 13 patient (65\%). 9 of them (45\%) had optimal technical success and 4 patients (20\%) had suboptimal technical success while the remaining 7 patients $(35 \%)$ had technical failure. Ruby et al. (2013) perform PTA 
for 413 patients with a technical success of $93 \%$ One and 6 month primary patency were $57 \%$ and $38 \%$ and limb salvage was $84 \%$ and $81 \%$, respectively. Sahin et al. (2018) reported limb salvage $73.6 \%$ of critical limb ischemia cases, complete wound healing in $67.8 \%$ of cases, and primary patency rate $32.5 \%$. Kristina et al. (2016) reported that technical success was $93 \%$. Average follow-up was 6 months At 1 and 3 months, freedom from restenosis, re-intervention, or amputation was $39 \%$ and $35 \%$, conventional primary patency was $53 \%$ and $51 \%$, and freedom from secondary restenosis and reintervention were $63 \%$ and $61 \%$, respectively. Limb salvage was $84 \%$ at 1 , 3 , and 6 months. Within 1 year, $15 \%$ underwent bypass and $18 \%$ underwent repeat infrapopliteal PTA. Ryu et al. (2012) attributed a high proportion of suboptimal results (22\%). Most of the suboptimal results involved diffuse and heavily calcified lesions, and had $30 \%$ to $50 \%$ of residual stenosis despite repeated balloon dilation.

\section{CONCLUSION}

Tibial angioplasty demonstrated its feasibility, safety and effectiveness in the treatment of diabetic patients with CLI.

\section{REFERENCES}

1. Capek P, McLean GK and Berkowitz HD, (2019): Femoropopliteal angioplasty. Factors influencing long-term Success. Circulation, 83(suppI. 2): 170-180.

2. Dorros G, Jaff MR, Murphy KJ and Mathiak L, (2018): The acute outcome of tibioperoneal vessel angioplasty in 417 cases with claudication and critical limb ischemia. Cathet Cardiovasc Diagn, 45:251 -256.

3. Frykberg R, Zgonis T. and Armstrong D (2017): Diabetic foot disorders: a clinical practice guideline. J Foot Ankle Surg, 45(5): 52-66.

4. Hynes N, Akhtar Y, and Manning B, (2014): Subintimal Angioplasty as a Primary Modality in the Management of Critical Limb Ischemia: Comparison to Bypass Grafting for Aortoiliac and Femoropopliteal Occlusive Disease J endovascular therapy, 11: 460-471.

5. Kristina A, Giles MD, Frank B, Pomposeli MD, Hamdan MD, and Seth B, (2016): Infrapopliteal angioplasty for critical limb ischemia: Relation of Trans-Atlantic Intersociety Consensus class to outcome in 176 limbs Journal of Vascular Surgery, 48, (1): 128-136.

6. Ruby C, Jeremy D, Rodney $P$ and Allen D, (2013): Outcomes following infrapopliteal angioplasty for critical limb ischemia Journal of Vascular Surgery, 57, (6) :1455-1464.

7. Ryu HM, Kim JS, Hong MK and Jang Y, (2012): Clinical outcomes of infrapopliteal angioplasty in patients with critical limb ischemia, Korean Circulation Journal 42(4): 259-265.

8. Sahin B, Berkan $O$ and Mustafa C (2018): six month outcomes of balloon angioplasty in the infrapopliteal arteries Sage Journals (26): 457-463.

9. Soder HK, Manninen HI, Jaakkola P, Pekka $M$ and Heikki T, (2010): Prospective trial of infrapopliteal artery balloon angioplasty for critical limb ischemia: angiographic and clinical results. J Vase Interv Radiol, 11: 10211031.

10. Tan M, Pua U, Wong D, Punamiya S, Chua G and Teo N (2010): Critical limb ischemia in a diabetic population from an Asian Centre. Biomedical Imaging and Intervention Journal, 6 (4) 33-36.

11. Todd JR, Ahanchi SS, Maurer CA, and Kim JK, (2013): Atherectomy offers no benefits over balloon angioplasty in tibial interventions for critical limb ischemia. J Vasc Surg, 58: 941-948. 


\section{تقييم التوسيع بالبالوز لتدخلات الأوعية تحت المأبضية لمرضى نقص

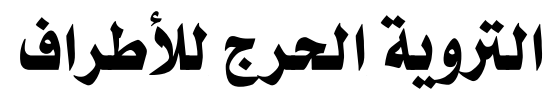

معاذ عبدالله رمضان، محمد كامل المزين، عبدالعزيز أحمد عبدالحافظ

قسم الجراحة العامة، كلية الطب، جامعة الأزهر، القاهرة

E-mail: drmizo9010@gmail.com

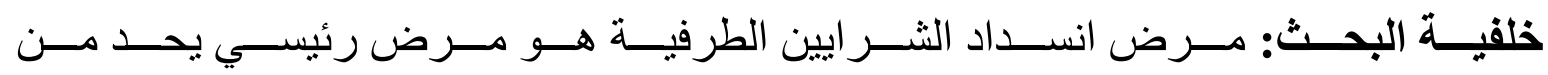

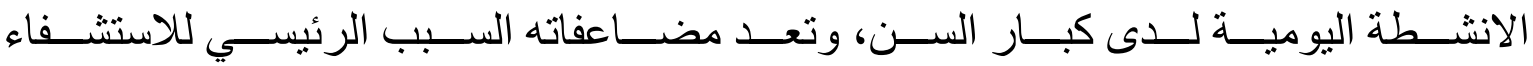

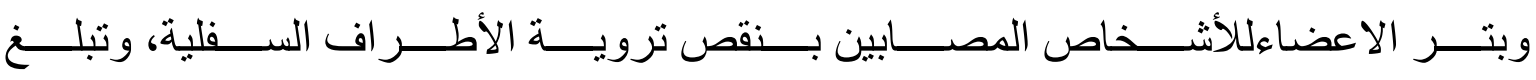
نفقاتهم مليار دو لار سنويًا في جميع أنحاء العالم.

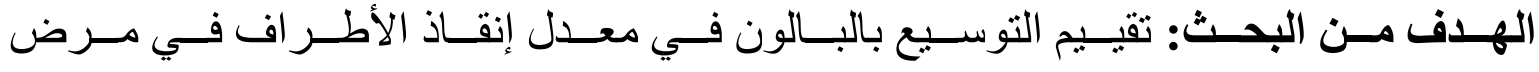
انسداد الثر ايين تحت المأبضية.

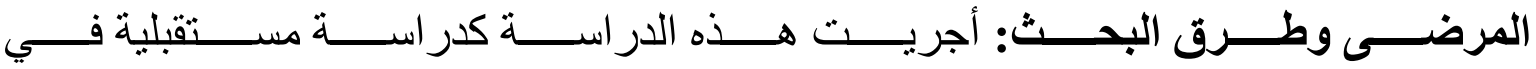

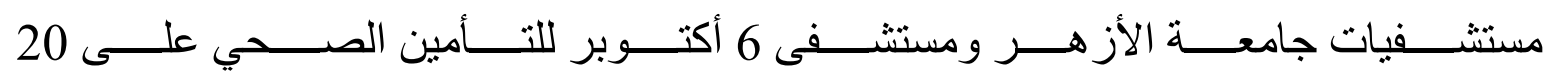

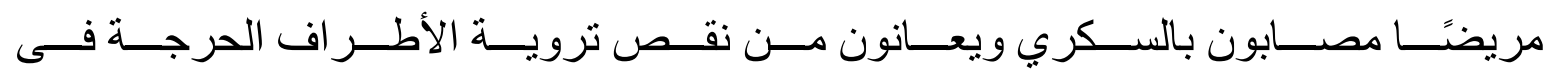
الفترة بين يناير 2019 ويوليو 2019.

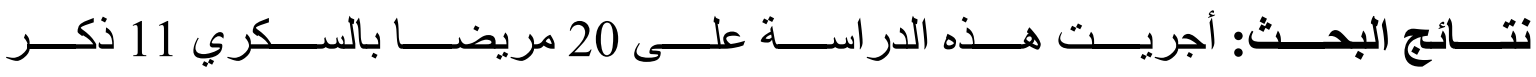

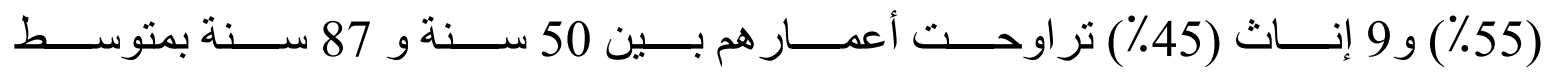

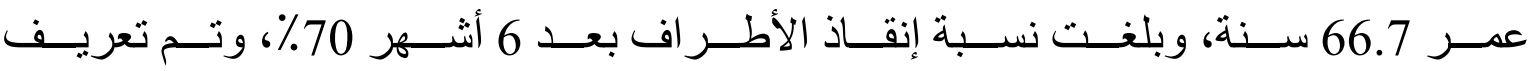

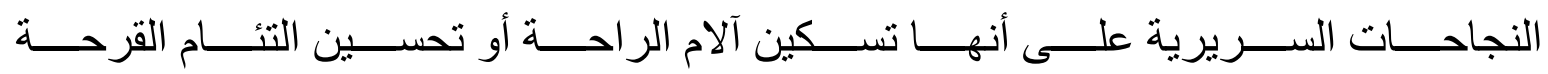

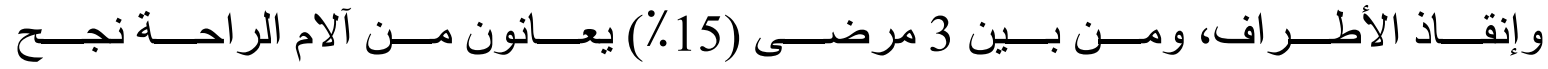

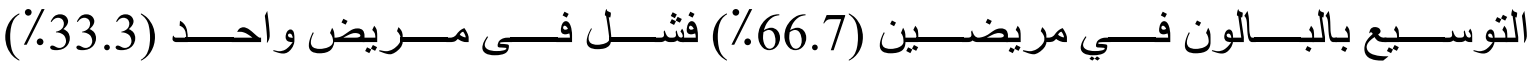

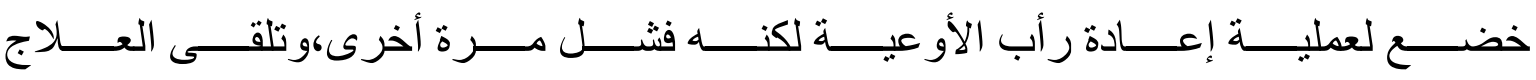

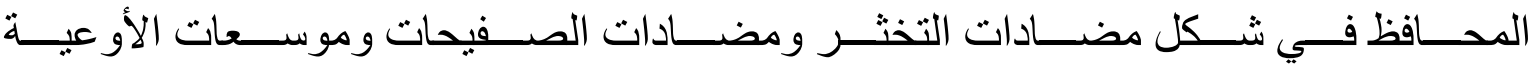

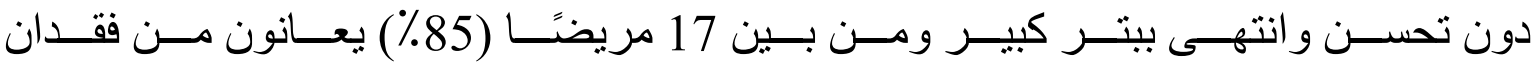

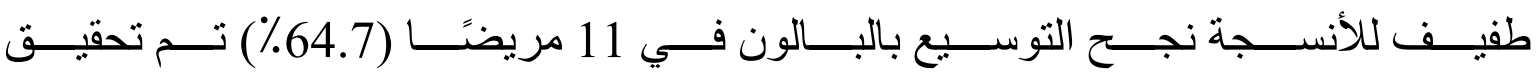




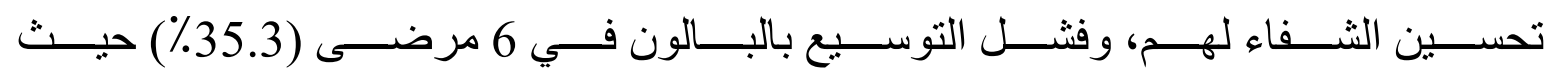

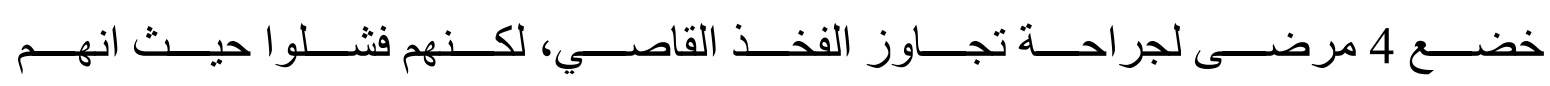

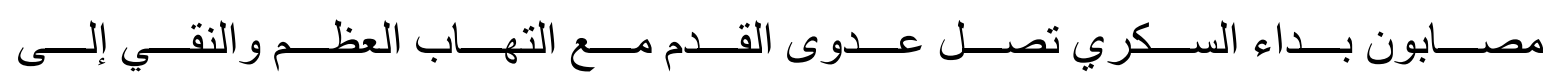

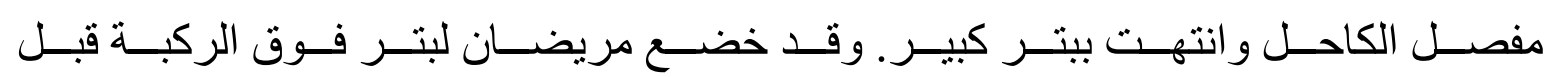

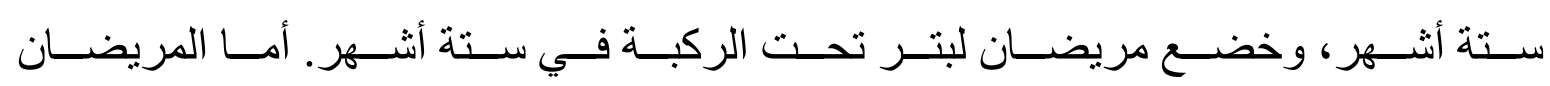

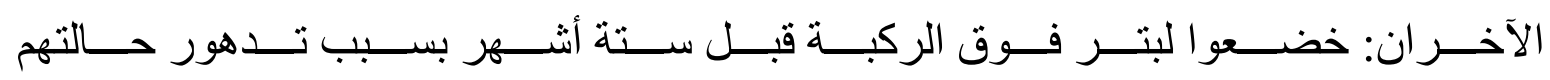
العامة.

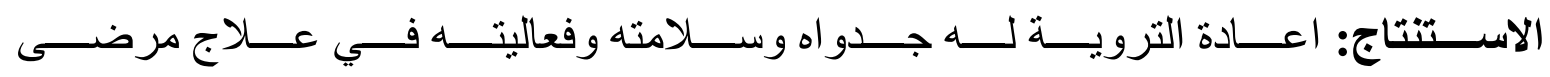
السكري الذين يعانون من نقص التروية الحرج للأطر اف. الكلمات الدالة: رأب الثرايين القصبية، اعتلال الثر ايين تحت المأبضية. 